\title{
The Role of Economic Factors in the Choice of Medical Providers in Rwanda \\ DOI: http://dx.doi.org/10.4314/rj.v3i1.4B
}

Ruhara Mulindabigwi Charles, University of Rwanda Urbanus Mutuku Kioko, University of Nairobi

\begin{abstract}
The purpose of this paper is to investigate the role of economic factors in choosing the alternative service providers and recommend suitable measures that could be taken to improve the use of health services in Rwanda. The study uses multinomial logit framework and employs the Integrated Household Living Conditions Survey (EICV2) conducted in 2005 by the National Institute of Statistics of Rwanda (NISR). To handle the problem of endogeneity, we estimate a structural model. The results point out that health insurance is an important factor of choice of health facilities. User fees are a major financial barrier to health care access in Rwanda. The results suggest that as household income increases, the patients shift from public to private health facilities where quality is assumed high. A number of policy recommendations emerge from these findings. First, as insurance is an important factor in choosing health care facility, policies that reduce health care cost would substantially increase the use of health services. Second, since an increase in income allows the patient to shift to private facilities, the government should consider subsidizing private health facilities to enable access of care in private sector by low-income households. Finally, since distance affects access to health care in Rwanda, there is need to improve geographical accessibility to health facilities across regions by upgrading and expanding transportation and health infrastructures.
\end{abstract}

Keywords: Health care. Price, Insurance, Income, Service provider and Multinomial logit.

\section{Introduction}

Health seeking behaviour is made on a number of dimensions. First, there is a choice of whether or not to seek formal medical care followed by the choice of what kind of health care a patient wishes to receive. Second, having made these choices, patients choose the type of provider facility to visit; public, private... (Mwabu, 1986). Analyzing the demand for health care by only focusing on whether or not a sick individual seeks formal health care can lead to incomplete analysis of the demand function because it does not consider valuable information on the choices of health service provider.

This suggests that a clear understanding of health seeking behavior can be obtained when in addition to identifying the factors influencing demand for health care, the determinants of choice of health facility are examined. While some of these input decisions might be based on recommendations made by the physicians, such recommendations may be altered with the level of expected price, income, insurance and other individual 
characteristics. Most of the studies on demand for health care focused on the quantity of health care (see Mocan et al., 2004; Hotchkiss et al., 2004; Feng et al., 2008; Lépine and Nestour, 2008; Hahn, 1994).

To our knowledge, there are no studies in Rwanda that have been done to determine factors influencing the choice of health facility. The available evidence on demand for health care by Jayaraman et al., (2008) and Shimeles (2010) focused on the decision to use maternal health care and the effects of community based health insurance schemes (CBHIs) at the district level. For countries in which estimates of choice of health facility exist, research results provide conflicting evidence to the effect of price, income and insurance across providers (Muriithi, 2013; Kaija and Okwi, 2011). The paper aims at filling the gap knowledge by examining the role of economic factors in the choice of alternative health facilities in Rwanda.

Identifying the determinants of facility choice is necessary so as to establish a complete picture of health seeking behavior of patients at different stages of the care decision process (Mwabu, 1986). In Kenya, Muriithi (2013) found that more than 70 percent of the respondents did not seek health care from government health facilities despite the fact that these facilities were the closest to them. Moreover, the private health facilities visited were more expensive than the closest, public health facilities. Thus, the information on facility choice can help a lot in explaining health service utilization in Rwanda. This paper provides the above kinds of evidence.

In addition, most of studies on demand for health care have not controlled for endogeneity of health insurance. Greene (2007) states that failure to address this problem leads to biased estimates. It is also possible that the types of data and econometric methods contribute to differences in estimates and thus alter accuracy in health care financing policies (Hunt-McCool et al., 1994). The paper addresses this estimation problem, providing rigorous evidence on determinants of choice of service providers that policy-makers can use to improve health service utilization across all the regions in Rwanda.

\section{Literature}

Mwabu (1986) documents that the choice of health care provider is based on utility maximization theory where the decision maker chooses the health facility that provides the highest utility. The choice made is not directly based on alternative facility, but rather on the characteristics or attributes of the alternative (Luce, 1959). In practice however, utility from any alternatives is driven by economic and other factors and the determination of which factor is or is not important in explaining the choice is an empirical matter.

Several studies have examined the role of price of health care in the choice of alternative providers (Sahn et al., 2003 and Akin et al., 1998). Their findings confirmed that if we control for quality of care, the price plays a significant role in the choice of service providers. However, the magnitude was found to be very small especially for public facilities. For instance doubling the price of public facilities was to induce a decline in the 
probability of their use by 0.10 while doubling the price of private clinics was accompanied by a large increase in the use of public clinics. Similar findings were reported by Mwabu et al., (1993) where a $10 \%$ increase in the price of public health facility reduced demand by only $1 \%$ while increasing the price of private facilities by $10 \%$ caused a decline of visits to private facilities by more than $15 \%$. Ssewanyana et al., (2004) documented that the low responsiveness to prices for public health facilities suggests that increasing user fees could generate more revenue for public health care providers without significantly reducing demand. Comparable results were reported by Muriithi (2009) who found user fees to be significantly correlated with the use of alternatives health facilities.

However, studies related to the effect of price on the choice of service providers were inconclusive because some of them reported insignificant price effect. Kaija and Okwi (2011) found that the effect of price on choice of any health facility was insignificant. This finding was attributable to the information asymmetry between the consumer and provider where consumer often does not have enough room information to make his own decision but has to rely on the prescriptions by the physicians. The insignificant price results were in line with Lacriox and Alilhonou (1982) and Akin et al., (1998) who found the price to have little effect on choice of providers. Given the conflicting results on the role of price of health care, more investigation is to be conducted.

The role of income in choosing alternative choices has been highlighted by many authors. Heller (1982) showed that the choice of service providers was inelastic to income. In addition, the choice of service provider among low income earners and high income individuals differed significantly. An increase in household income level was associated with a reduction in seeking treatment from public health facilities and consequently an increase in demand for private health services. Such behavior is quite rational given that it is well known that with higher incomes, access to high quality service in private facilities become possible. Similar findings established that women from wealthy households were more likely to deliver a child at hospital assisted by medical personnel (Jayaraman et al., 2008).

If the results above imply that household income is an important factor in explaining the choice of service delivery, other studies moderated the effect of income on health seeking behaviour. Linndelow (2002) reported insignificant difference between poor and non-poor on the choice of alternative health facilities. This was explained by the complex way through which income variable is measured in the model. Income proxied by total expenditure first entered directly in the model, but also through incomeprice interaction, and finally, through opportunity cost of time. Since the role of income differed across studies and services provider, more studies are needed.

Other studies have examined the role of nonmonetary factors in determining the choice of health care providers (Acton, 1975 and Mwabu, 1989b). Both studies used a utility maximization model to develop predictions for free and non-free care of user fees in New York and Kenya respectively. The results showed that non-monetary factors such as distance to health care from 
home, a proxy for price of health care influences the choice of alternative health facilities. In support of this view Awoyemi et al., (2011) reported a negative and significant effect of the distance to hospital from the area of residence on the utilization of both public and private hospitals.

The results implied that the longer the distance to the hospital from home, the less the utilization of private hospitals and the more the people living in rural areas would show preference for no-care or self-treatment. The results were consistent with the findings by Ssewanyana et al., (2004) who found a negative effect of distance to health service provider suggesting that the probability of seeking care from any formal provider decreases with distance. However, Mwabu, et al., (2003) found distance to have little effect on demand for health care services. The plausible reason for this finding was that majority of people reported residing within $3 \mathrm{~km}$ of a health facility suggesting that health facilities in the study area were accessible to the population.

Individual and household characteristics play an important role in choosing the service providers (Linndelow, 2002). Research has shown that household characteristics such as age influence the choice of service providers. Old age tended to be associated with a decrease in the probability of seeking care from a public hospital or health post. Relative to the category of children under the age of 5 years, the group aged 50 years and above was found to be less likely to seek care from private clinics but was more likely to obtain care from public clinics and hospitals (Kaija and Okwi, 2011). Other studies showed that old age tended to be associated with an increase in the probability of seeking care from a traditional medical practitioner and a decrease in the probability of care being sought at a hospital (Linndelow, 2002). The research showed that the most important effect was the shift away from consultation at a health post to noconsultation as age increased.

Research has reported inconclusive evidence on gender effect (Ssewanyana et al., 2004; Mwabu et al., 1993; Sahn et al., 2003 and Hutchinson, 1999). Although distance and user fees reduced access to health care, men were less constrained by distance than women. Males were less likely to seek care from public facilities relative to no-care, and the researcher considered that the differences in education were the main reason (Wong et al., 1987). In most studies, relative to the self- treatment option, females were more likely to seek care from public health facilities compared to men who had high probability of seeking care from private health facilities. Men's demand for private health care increased with age and reflecting that as men age they encounter increasingly serious illnesses that can only be treated by the better equipped private facilities.

As with females, the probability of men seeking government health care started to decline as they aged (Lawson, 2003). In some other studies however, gender effect on alternative choices was ambiguous leading to a narrowing of the gap of gender disparities. There was no evidence of gender differences in health care seeking (Ssewanyana et al., 2004). Gender disparities were also examined for children. The findings were such that if income plays an important role in raising the health care demand for 
children, boys were more likely to seek care when in richer households and less care when in poorer households than girls (Ssewanyana et al., 2004).

Other studies have included the household size in the determinants of choice of service providers (Sahn et al., 2003). The effect of household size on the choice of alternative providers was found to be significant. The negative effect of household size confirmed the notion of competition for resources in larger households. Individuals from large size households were less likely to choose private health facilities probably due to high costs. Households with large number of people are financially limited and thus not likely to seek care from private clinics due to high costs and instead rely on self-treatment at home.

Results from empirical studies on choice of service providers have differed in several ways. Some of the studies reviewed found a statistically significant or insignificant positive relationship between income and alternative facilities. The results discussed above show inconsistency in terms of the effect of price, income and other variables. Because noconsensus has emerged, this paper seeks to present new evidence of the role of economic factors on the choice of service providers in Rwanda. In addition, most of the studies on choice of health provider did not address the endogeneity and heterogeneity issues.

\section{Data and Methodology}

The data used in this paper is drawn from the Integrated Household Living Conditions survey (EICV2) conducted in 2005 by the National Institute of Statistics of Rwanda (NISR). This nationally representative survey collected data from 7,620 households and 34,819 individuals. Data was collected at the household and the individual level. The EICV2 aimed at enabling the government to assess the impact of the different implemented policies and programs in improving the living conditions of the population in general. The survey covered all the 30 districts in Rwanda and collected data on a wide spectrum of socioeconomic indicators, labour, housing, health, agriculture, debt, livestock, expenditure and consumption in different areas, regions and locations of the country.

Household level information included consumption expenditures on health, OOPE (consultation; laboratory tests; hospitalization; and medication costs). Individual level information included socio-economic indicators and insurance status. There were also a number of community variables such as distance to the nearest health facility. In order to estimate the choice of service providers we constructed a sub-sample for choice of service providers. We considered this data set although collected in 2005 as suitable for capturing the demand effects because household dynamics and responses do not change too frequently.

In this paper, we assume that an individual selects a service provider conditional on having decided to seek formal health care. The framework is based on Gertler et al., (1987), and Ssewanyana et al., (2004) where the decision to choose an alternative facility is influenced by economic and other factors. Because the choice of health service provider is a discrete type 
of decision, probabilistic choice models are a better theoretical representation for estimating choice of service provider (McFadden, 1981). The assumption is that in the event of illness, a household's decision to seek medical treatment for a sick member can be viewed as being influenced by the household's own characteristics and attributes of the available health care providers.

\section{Figure 1: The Choices of Service Provider when ill}

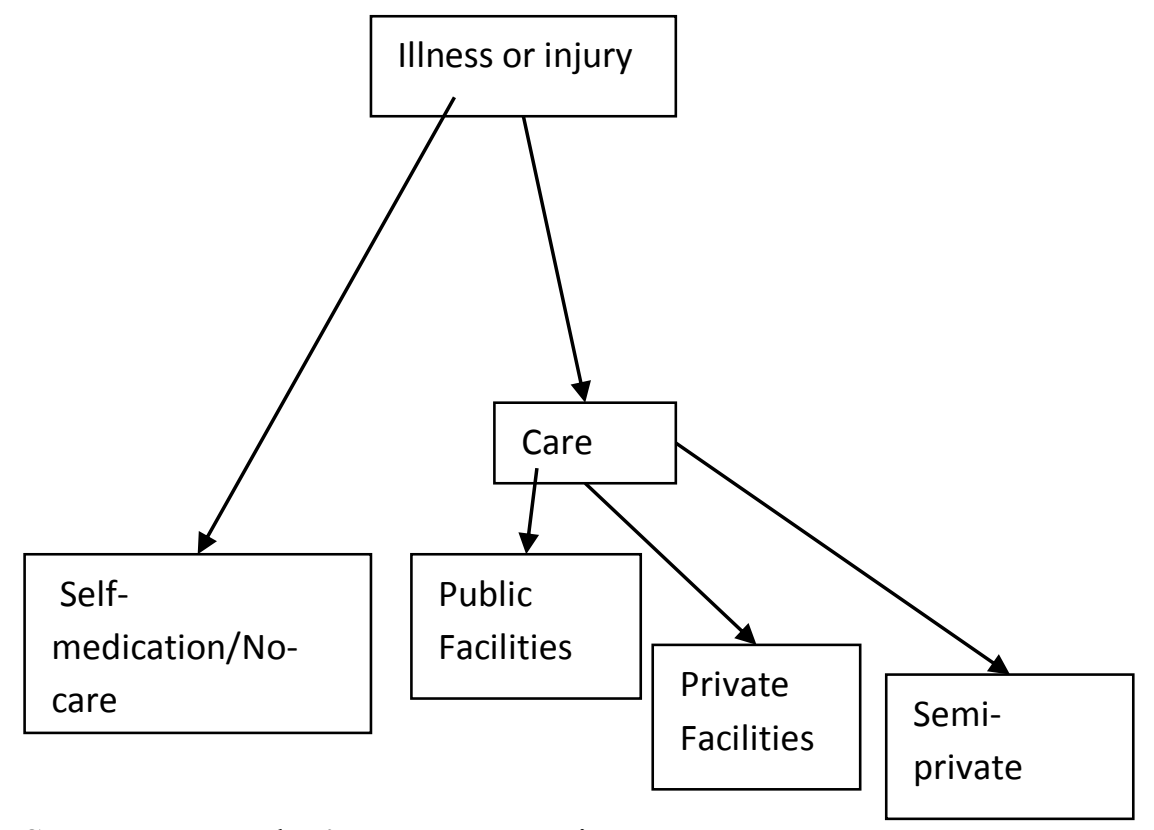

Source: Researcher's own construction

Based on the data set, the choice structure in Rwanda comprises four choices of health care providers; public providers, private providers, semiprivate providers and self-medication. When ill or injured, an individual chooses whether or not to seek health care and once the decision is made, the patient chooses one of the four available alternatives as shown in figure 1 above. The alternatives might include self-care, no-care, pharmacy, public clinics/hospitals, private hospitals/clinics, semi-private hospitals/clinics and others.

In this study visits are limited to one consultation only. If several consultations were made in the last 15 days, answers referred to the last consultation. Because the number of observations in some cases was small, the alternatives were grouped into four options: (1) Self-medication including no-care, pharmacy/drug shop and traditional healers (See Odwee et al, 2006; Kaija and Okwi, 2011 and Lawson, 2004). (2) Public facilities including all government health providers; hospital, clinics, dispensaries and health centres. (3) Private facilities; privately owned hospital, clinics, dispensaries and health centres. (4) Semi-private facilities owned by private but subsidized by the government. This group includes the faith-based facilities run by religious organizations such as the Catholic, Protestant or others. 
The patient chooses the provider option that maximizes his/her utility given the individual's illness, the economic actors (fee charged by a particular provider and the level of income) and considering the type insurance. With some modifications, the utility function of the choice model is expressed as in Ssewanyana et al., (2004) as follows:

$$
U_{i j}=U_{i j}\left(H_{i j}, E_{i j}\right)
$$

where $H_{j}$ is the level of health expected by individual i after being treated by $\mathrm{j}^{\text {th }}$ service provider (or treatment in $\mathrm{j}^{\text {th }}$ place); $E_{j}$ are expenditures in all other goods given that the $\mathrm{j}^{\text {th }}$ choice is made. The consumer decides first to demand care against no-care. Conditional on this decision, the individual chooses the provider expected to yield the highest satisfaction. Supposing that there are $\mathrm{J}+1$ feasible alternative (where $\mathrm{j}=0$, alternative being self-care or no-care), then, the unconditional utility maximization will be given by:

$$
U^{*}=\max \left(U_{o}, U_{1} \ldots, U_{j}\right)
$$

Where $U^{*}$ is the highest level of utility the individual can obtain. This is obtained by comparing the different utility levels obtainable from each alternative facility, varying from 0 to $j$.

Based on equation (1), the health production function can be formulated as:

$$
H_{i j}=h\left(S_{i}, Q_{j}\right)+\varepsilon_{i j}
$$

where $H_{i j}$ is the improvement in health by individual $\mathrm{i}$ after being treated by the $\mathrm{j}^{\text {th }}$ provider, which is a function of economic factors; income and price, individuals characteristics including age, sex, education etc. and household level factors including insurance and household size,. $S_{i}$ represents specific factors to a provider such as qualified health staff, $Q_{j}$ represents unobservable heterogeneity characteristics at individual, household and facility level while $\varepsilon_{i j}$ is the error term. In case of self-medication option, $H_{i j}$ is equal to zero because we assume that there is no improvement in health status for those who do not consume health services.

After consulting $\mathrm{j}^{\text {th }}$ provider, the disposable income by the individual $\mathrm{i}^{\text {th }}$ is a function of her/his individual income, $B_{i}$; and the charge, $C_{j}$, that she/he pays at the $j^{\text {th }}$ provider representing both direct costs such as user fees and indirect costs such as transportation cost to the health facility from home. The relationship is expressed as:

$$
D i_{i j}=f\left(B_{i}-C_{j}\right)
$$

The equation states that the individual $i^{\text {th }}$ disposable income $D_{i j}$ when $j^{\text {th }}$ provider is chosen is a function of the individual income $B_{i}$ and the direct and indirect charges $C_{j}$ at the $j^{\text {th }}$ provider.

Substituting equations (4) and (3) into (1) gives the conditional utility function expressed as: 
$U_{i j}=h_{i j}\left(S_{i}, Q_{j}\right)+f\left(B_{i}-C_{j}\right)+\varepsilon_{i j}$

The equation says that the maximum utility by individual $i$ is obtained by choosing the $\mathrm{j}^{\text {th }}$ service provider taking into consideration the individual budget (income), direct costs such as charges by the provider and the indirect costs such as the transportation costs. The other variables in equation (5) are explained as in equations (3-4).

Noting the deterministic part of equation (5) as $V_{i j}$, the equation can further be expressed as:

$U_{i j}=V_{i j}+\varepsilon_{i j}$

where the $i^{\text {th }}$ individual chooses the $j^{\text {th }}$ health service provider from which he/she expects to get the greatest level of utility. Any service provider is chosen if the expected utility is higher than the satisfaction that could be derived from all other service providers. Then, an individual chooses the alternative that maximizes the welfare utility which also reflects his/her future health state. He or she chooses an alternative from a set of $j$ 's, $j \in J=\{0,1, \ldots, m\}$ where 0 is no-care (self-medication) and $\mathrm{j}=1 \ldots \mathrm{m}$ are the other choice alternatives. The provider $\mathrm{j}$ will be chosen by individual if:

$$
U_{i j}>U_{i k} \text { where } \quad j \neq k \text { and } \quad \mathrm{j}, \mathrm{k} \in \mathrm{J}
$$

Equation (7) says that individual $i$ will choose the health service provider $\mathrm{j}$ if and only if the expected utility from health service provided by the $\mathrm{j}^{\text {th }}$ provider is strictly greater than the expected utility from any other health service providers. This means that the probability of a given medical care provider against all other providers is:

$$
\begin{aligned}
& P_{M C}=P\left(U_{M C} \geq U_{\text {OTHER }}\right) \\
& \quad=P\left[V_{M C}+\varepsilon_{M C} \geq V_{\text {OTHER }}+\varepsilon_{\text {OTHER }}\right) \\
& \quad=P\left[V_{M C}-V_{\text {OTHER }} \geq \varepsilon_{\text {OTHER }}-\varepsilon_{M C}\right]
\end{aligned}
$$

Where $\mathrm{P}_{\mathrm{MC}}=$ probability of choosing a given medical care provider, $\mathrm{U}_{\mathrm{MC}}=$ the utility from the visited medical provider and $\mathrm{U}_{\text {ОтнЕR }}=$ the utility from all other medical providers.

The equation says that a given medical care provider is chosen if the expected utility once visited is greater than the utility from any other health providers. For instance, an individual will choose a public health facility for treatment if

$$
\begin{aligned}
P_{P U B} & =P\left(U_{\text {PUB }} \geq U_{\text {OTHERtype }}\right) \\
& =P\left[V_{\text {PUB }}+\varepsilon_{\text {PUB }} \geq V_{\text {OTHERTYPE }}+\varepsilon_{\text {OTHERTYPE }}\right] \\
& =P\left[V_{\text {PUB }}-V_{\text {OTHERTYPE }} \geq \varepsilon_{\text {OTHERTYPE }}-\varepsilon_{\text {PUB }}\right]
\end{aligned}
$$

Where $\mathrm{P}_{\mathrm{UB}}=$ probability of choosing public medical care provider, and $\mathrm{U}_{\text {OTHER }}=$ the utility from all other medical providers. That is, a public health 
facility is chosen if the utility to be derived once visited is greater than the utility from any other type of service providers.

Conversely, a private health facility will be chosen for treatment if the utility to be derived once visited is greater than the utility from any other type of health facilities. This is expressed as in equation 10 :

$$
\begin{aligned}
& P_{R I}=P\left(U_{\text {PRI }} \geq U_{\text {OTHERtype }}\right) \\
& \quad=P\left[V_{\text {PRI }}+\mu_{\text {PRI }} \geq V_{\text {OTHERTYPE }}+\varepsilon_{\text {OTHERTYPE }}\right] \\
& P\left[V_{\text {PRI }}-V_{\text {OTHERTYPE }} \geq \varepsilon_{\text {OTHERTYPE }}-\varepsilon_{\text {PRI }}\right]
\end{aligned}
$$

Where $\mathrm{P}_{\mathrm{RI}}=$ probability of choosing a private medical care provider, $\mathrm{U}_{\text {OTHER }}=$ the utility from other all other medical providers.

If in equation (10) $h\left(S_{i}, Q_{j}\right)$ is linear in $\mathrm{S}_{\mathrm{i}}$ and $\mathrm{Q}_{\mathrm{j}}$, we can denote the coefficient vectors of $\mathrm{S}_{\mathrm{i}}$ by $\delta_{j}$ and those for $\mathrm{Q}_{\mathrm{j}}$ will be denoted by $\gamma_{j}$ which might vary across alternative providers. To avoid responsiveness of prices being independent of income we consider a non-linear specification of $f\left(B_{i}-C_{j}\right)$ (See Gertler et al., 1987, Gertler and Van der Gaa, 1990 and Ssewanyana et al., 2004). As specified in Sahn et al., (2003) and Ssewanyana et al., (2004) we employ a quadratic utility function linear in health goods and quadratic in the logs of consumptions of non-health goods. This is given by:

$$
f\left(B_{i}-C_{j}\right)=\phi_{1} \ln \left(B_{i}-C_{j}\right)+\phi_{2}\left[\ln \left(B_{i}-C_{j}\right)\right]^{2}
$$

Where $\phi_{\mathrm{s}}$ are assumed to be equal across provider options. Sahn et al., (2003) shows further that the equation can be reduced to

$$
f\left(B_{i}-C_{j}\right) \approx \kappa_{1}\left[\ln \left(B_{i}\right)-C_{j} / B_{i}\right]+\kappa_{2}\left[\ln \left(B_{i}\right)^{2}-2 \ln \left(B_{i}\right)\left(C_{j} / B_{i}\right)\right]
$$

The equation (12) shows that the functional form for prices and income is quadratic in the logs of net income.

Given that $\ln \left(\mathrm{B}_{\mathrm{i}}\right)$ and $\ln \left(\mathrm{B}_{\mathrm{i}}\right)^{2}$ are constant across provider options it is better to use the difference in utilities, $\mathrm{V}_{\mathrm{ij}}-\mathrm{V}_{\mathrm{i} 0}$, where $\mathrm{V}_{\mathrm{i} 0}$ is a reference utility, which in this case refers to no-care and can be normalized to zero.

Then, the equation to estimate is obtained by getting the difference in utilities as shown in equation (13) below:

$$
V_{i j}-V_{i 0}=\delta S_{i}+\gamma Q_{j}+\kappa_{1}\left(-C_{j} / B_{i}\right)-\kappa_{2}\left[2 \ln \left(B_{i}\right)\left(C_{j} / B_{i}\right)\right]
$$

The empirical model commonly used in the empirical literature to estimate the choice of health provider is Multinomial logit (see Li, 1996; Lawson, 2004). The problem of this model is that it imposes the property of independence of irrelevant alternatives (IIA), an assumption of nocorrelation between the error terms of the different choices. The assumption of IIA states that the odds of facility type $i$ being chosen over facility type $k$ are independent of the availability alternatives other than $i$ and $k$. 
An interesting feature is that the odd of choosing a given alternative does not depend on how many alternatives there are in total because each alternative has its own value independent of the other alternatives. With this, we would expect that if there were three options, and one were removed, people would still choose among the remaining two in the same proportion as they did when there were three. The model cannot be appropriately applied when there are different degrees of substitutability or complementarity among the various choices. The alternative model in this case is the nested logit allowing the correlation of some of the choices.

However, given the nature of the choice structure in Rwanda and considering that the dataset used in this paper contains a one-level four choices of health care providers self-treatment, public, private and semiprivate, we cannot use the nested logit model ${ }^{5}$. Instead, we adopt Multinomial logit model to estimate the choice of service providers. This option is supported by McFadden (1981) who argued that Multinomial Logit should be used when outcome categories are plausibly independent for each one of the decision makers. In addition, the Hausman test for IIA showed that the 4 alternatives are independent ${ }^{6}$ (See Appendix Table A3). Moreover, the test statistic cannot reject the null, i.e., the choice alternatives are uncorrelated (see also Hausman and MacFadden, 1984).

In estimating the choice model, we assume that each individual has four different providers available: the nearest public provider, the nearest private provider, the nearest semi-private provider and the self-medication alternative. Self-medication includes traditional healers, no-care as well as retail drug shops (Odwee et al., 2006).

Given the assumption, the probability that the $\mathrm{j}^{\text {th }}$ provider is chosen given other providers is expressed as in Scott Long (1997), Kaija and Okwi (2011) and Lawson (2004) as follows:

$$
\operatorname{Pr}\left(Y_{i}=j / x_{i}\right)=\frac{\exp \left(x_{i} \beta_{j}\right)}{1+\sum_{j=2}^{J} \exp \left(x_{i} \beta_{j}\right)}, j>1
$$

Where $i$ refers to the individual in a household; $\mathrm{j}$ indexes the service provider (self-medication, public, private or semi-private and $X_{i}$ are covariates including income, user fees, health insurance. $\beta_{j}$ are the parameters to estimate. $\beta_{j}$ is constrained to equal zero because one is the reference alternative $\left(\beta_{1}=0\right)$. We use this model to test whether or not the

\footnotetext{
${ }^{5}$ To be used, Nested Logit requires a two-level sub groups with possibility of correlation of different choice alternatives. For instance, the two levels would be public and private health providers (first level) and each one being divided into hospitals and clinics (second level).

${ }^{6}$ We conducted the test for IIA as reported in table A3 in the appendix. The test performed on the independence of the four alternatives was conclusive showing that the alternatives are independent.
} 
effects of determinants (such as user fees, income, and insurance) differ across service providers.

Marginal effects can be computed for all the independent variables in order to obtain probability that a particular provider or alternative will yield the greatest amount of utility. The marginal effect of a variable $x$ on alternative $j$ refers to a change in the probability of individual $i$ choosing alternative $j$ in response to a change in the variable $x$. This can be computed using the multinomial logit functional form as:

$$
\frac{\partial \operatorname{Pr}(Y=1)}{\partial X_{i}}=\operatorname{Pr}\left(Y_{j}=1\right)\left[\beta_{j, x}-\sum_{j=1}^{J} \beta_{j, x} \operatorname{Pr}\left(Y_{j}=1\right), j>1\right.
$$

where $\beta_{j k}$ are the alternative specific coefficients associated with variable $x$. In this case, we observe that the marginal effects depend on the values of all explanatory variables and the coefficients for each outcome.

Due to reverse causality, one of the independent variables, health insurance is endogenous and the estimation has to address this problem. Endogeneity is due to the reverse causality between health insurance and demand for health care. So, in order to obtain unbiased and consistent estimates, instrumentation of the endogenous variable is required. The instrumental variable should be correlated with the endogenous regressor but unrelated directly to the dependent variable (Ajakaiye and Mwabu, 2007). Estimating the choice equation without taking into account this problem might result in biased estimates (Rosenzweig and Schultz, 1982).

To address the problem of endogeneity of insurance, we used Waters (1999a). A reduced-form of health insurance demand was estimated using logistic regression by including all independent variables in the demand equation and the instrumental variables. We then generated the predicted values and included them in the choice of provider's equation together with the actual observed values of the insurance variable. The decision rule is that in case the null hypothesis of the coefficient of the predicted values of health insurance is equal to zero cannot be rejected, there is no-strong correlation between health insurance variable and the error-term. This would mean that, insurance is an exogenous variable (Waters 1999a). The instrumental variables included the employment status (employed or not employed) and the relationship to household head.

We tested for both the endogeneity of insurance and the validity of instruments. We carried out the test for endogeneity of health insurance by using the Durbin-Wu-Hausman test. The results showed that the Durbin$\mathrm{Wu}$-Hausman statistic values were significant at the 10 percent level. This result was further in favour of estimating structural rather than reduced form demand for choice of service providers. We also tested the impact of the instruments on the dependent variable. These were found to be insignificant. The strength of the instruments was tested by considering the impact of the instruments on endogenous variable. As the coefficients on instruments were large and significant at the 1 percent level, the instruments were strong. In addition, we conducted the F-test to check the role of the 
instruments on the endogenous variable. While an F-statistic of at least 10 is recommended (Kioko, 2008; Staiger and Stock, 1997), the minimum Eigen value statistic for F-test was 97.2 suggesting that the null hypothesis of weak instrument had to be rejected.

In addition, as we had two instruments and only one endogenous variable; there was then possibility of over-identification of the structural model. This means that one or more instruments may be correlated with the stochastic error-term (Wooldrige, 2002). It was then necessary to test if the model was correctly specified and that the instruments are valid. We carried out the Sargan and Basmann tests of over- identifying restrictions. The Sargan test of over-identifying restrictions was $(0.45036$; $p$-value $=0.5732)$ while the Basmann test of over-identification restrictions was $(0.45024 ; \mathrm{p}$-value $=$ 0.5733 ). With these values, the results could not reject the null hypothesis of no-correlation and instead suggested that the instruments were valid and uncorrelated with the stochastic error-term.

\section{Results and discussion}

Table 1 reports the parameter estimates of the role of economic and other factors on the choice of service providers and their z-statistics while Table A2 reports the marginal effects. The choice options are: self-medication, public provider, private provider and semi-public provider. Self-medication is the reference category.

The household income is significantly correlated with the probability of using the provider' services. For instance, income is positively related to choosing a private provider. Its coefficient is significant at the 1 percent level suggesting that while holding all other variables constant, if income increases by 1 Rwandan Franc (FRW), the expected utility of choosing a private provider would increase by 0.0004 . The reason for this is that high income individuals perceive that public providers offer lower quality services while private providers offer better quality services. However, the coefficient of public provider was negative implying that the probability of seeking health care from public provider drops as income increases. The result finds support in Kaija and Okwi (2011) who showed that health seeking behaviour of low and high income individuals differ significantly.

Insurance is an important factor explaining the choice of public and private treatment alternatives in Rwanda. The predicted values of insurance were included in the model to test for endogeneity in the model. As they were significant at the 5 percent level for both public provider and private provider and at 10 percent level for semi-private provider, treating insurance as exogenous would yield a correlation between health insurance variable and the error-terms. This supports the need of estimating a structural model of choice of service providers rather than its reduced form. The finding is comparable to that of Jowett et al., (2004) who reported that individuals without or with less generous insurance coverage tended to use public providers to a far greater extent than those with a more generous insurance scheme. 
The monetary price has a negative and significant impact on the choice of private health facilities. The result suggests that as the private hospital/clinic charges increase by $1 \mathrm{FRW}$, the log odds of visits by patients reduce by 0.95 and these shift to self-medication. However, the coefficient on fees for public health facilities is unexpectedly positive indicating that the price charged by public health facilities is not enough to discourage the patients since it remains affordable. The direct implication is that increasing user charges decreases the likelihood of seeking health care from private health provider relative to self-medication. The findings were in line with Cisse (2006); Yoder (1989); Dow (1995); Mwabu et al., (1993); and Mwabu et al. (1989b) who found negative user fees effects on health seeking behavior.

The distance to health care from the area of residence seems to discourage the choice of public and semi-private health facilities. Thus, increasing distance induces an increase of the likelihood of a household member opting for self-treatment. The negative sign is not surprising since the distance to health care is highly related to the transportation cost. Muriithi (2013) showed that an increase in distance induces a payment of some extra cost to travel to the source of treatment as opposed to seeking self-treatment. The results support the findings by Ssewanyana et al., (2004), Lawson (2004) and Awoyemi et al., (2011) who argued that distance reduces the probability of using distant service providers. However, the distance to health facility from home is positively associated with the choice of a private health facility. This means that distance to private health providers is perceived to be associated with quality of health care. In this case, private health facilities although distant are chosen provided their quality services is perceived to be high. This result is in line with Bolduc et al., (1996) who showed that distance to health care measured by travel cost was positively related with the probability of seeking health care at private facilities.

The results further showed that regions have an influence on choice of service providers. For instance, the coefficient on Kigali dummy relative to East was positive and significant for the choice of private suggesting that living in Kigali as compared to Eastern region increases the perceived treatment benefit of a private health provider. This result finds supports in Brown (2002) who noted that there were regional differences in probabilities of using health facilities. Age was found to have positive effect on the choice of private health facilities in Rwanda. The results implied that as one ages, the relative chance of choosing a private health provider increases. The reason behind is related to the ability to afford payment because income rises with age. The study did not find meaningful results relating to the effect of gender on the choice of health providers because all the three coefficients of gender were statistically insignificant. Similar findings were reported by Sahn et al., (2003) and Ssewanyana et al., (2004).

Given the above results, a number of policy recommendations emerge. Since price, income and insurance are important determinants of health care seeking behaviour in Rwanda, policies that reduce health care cost would substantially increase the use of health services. The government should also consider subsidizing private health facilities to guarantee access care of 
private sector by low-income households. Since distance, location and region-specific factors are important drivers of the choice of service providers, it is clear that there are regional hindrances to health care access. The government should explore ways of implementing a voucher scheme to boost rural incomes in specific regions. Despite widespread insurance coverage, there exists large difference in regional access to health care in Rwanda (Endo, 2004). The government should ensure a balanced geographical accessibility to health care delivery based on population need. The government should also expand or improve transportation infrastructures such as roads, telecommunication, and other health infrastructures in different areas to make health care providers more accessible.

Table 1: A Multinomial Logit Model of Provider Choice Estimates (zStatistics in parentheses)

\begin{tabular}{|c|c|c|c|}
\hline Variables & $\begin{array}{l}\text { Public provider } \\
\text { (Coefficient } \\
\text { estimates) }\end{array}$ & $\begin{array}{l}\text { Private provider } \\
\text { (Coefficient } \\
\text { estimates) }\end{array}$ & $\begin{array}{l}\text { Semi-private } \\
\text { provider } \\
\text { (Coefficient } \\
\text { estimates) }\end{array}$ \\
\hline $\begin{array}{l}\text { Household } \\
\text { income }\end{array}$ & $-0.0003(-.67)^{* *}$ & $0.0004(3.01)^{* * *}$ & $-0.00026(-0.52)$ \\
\hline User fees & $0.72(6.70)^{* * *}$ & $-0.95(-6.70)^{* * *}$ & $0.065(0.34)$ \\
\hline $\begin{array}{l}\text { Quality of } \\
\text { health care } \\
\text { (=1 if medical } \\
\text { specialist in } \\
\text { the visited } \\
\text { health facility } \\
\text { exists, and } 0 \\
\text { otherwise) }\end{array}$ & $-0.209(-2.73)^{* *}$ & $0.409(2.73)^{* *}$ & $-0.169(-0.84)$ \\
\hline Insurance $(=1)$ & $0.34(3.8)^{* * *}$ & $3.1(4.3)^{* * *}$ & $0.345(1.8)^{*}$ \\
\hline $\begin{array}{l}\text { Predicted } \\
\text { values } \\
\text { insurance }\end{array}$ & $3.15(2.66)^{* *}$ & $3.435(2.61)^{* *}$ & $5.326(1.91)^{*}$ \\
\hline $\begin{array}{l}\text { Distance to } \\
\text { the health } \\
\text { facility }\end{array}$ & $-0.31(-2.36)^{* *}$ & $-0.455(-2.36)^{* *}$ & $-0.956(-4.06)^{* * *}$ \\
\hline $\begin{array}{l}\text { Household } \\
\text { size }\end{array}$ & $0.035(1.37)$ & $-0.0357(-1.37)$ & $0.0403(1.27)$ \\
\hline
\end{tabular}




\begin{tabular}{|c|c|c|c|}
\hline Variables & $\begin{array}{l}\text { Public provider } \\
\text { (Coefficient } \\
\text { estimates) }\end{array}$ & $\begin{array}{l}\text { Private provider } \\
\text { (Coefficient } \\
\text { estimates) }\end{array}$ & $\begin{array}{l}\text { Semi-private } \\
\text { provider } \\
\text { (Coefficient } \\
\text { estimates) }\end{array}$ \\
\hline Age & $-0.009(-2.48)^{* *}$ & $0.009(2.48)^{* *}$ & $-0.007(-1.39)$ \\
\hline $\begin{array}{l}\text { Transportatio } \\
\mathrm{n} \text { cost }\end{array}$ & $0.00006(1.16)$ & $-0.00006(-1.16)$ & $0.00006(1.12)$ \\
\hline Primary $(=1)$ & $0.456(2.9)^{* *}$ & $0.011(1.7)^{*}$ & $0.003(0.96)$ \\
\hline $\begin{array}{l}\text { Secondary } \\
(=1)\end{array}$ & $0.675(3.9)^{* * *}$ & $0.023(4.7)^{* * *}$ & $0.764(0.67)$ \\
\hline Tertiary $(=1)$ & $0.0005(0.9)$ & $0.0002(5.9)^{* * *}$ & $0.0005(2.12)^{*}$ \\
\hline $\operatorname{Male}(=1)$ & $-0.153(1.22)$ & $0.153(1.22)$ & $-0.031(-0.18)$ \\
\hline Urban $(=1)$ & $-0.82(-3.22)^{* * *}$ & $0.821(3.22)^{* * *}$ & $-0.85(-2.69)^{* *}$ \\
\hline $\begin{array}{l}\text { Kigali region } \\
(=1)\end{array}$ & $\begin{array}{l}-0.6166 \\
2.74)^{* *}\end{array}$ & $0.8212(2.74)^{* *}$ & $-1.35(-4.09)^{* * *}$ \\
\hline $\begin{array}{l}\text { Southern } \\
\text { region }(=1)\end{array}$ & $0.16(0.82)$ & $-0.16(-.82)$ & $0.54(2.37) * *$ \\
\hline $\begin{array}{l}\text { Western } \\
\text { region }(=1)\end{array}$ & $-.1451(-0.76)$ & $0.145(0.76)$ & $0.82(3.67)^{* * *}$ \\
\hline $\begin{array}{l}\text { Northern } \\
\text { region }(=1)\end{array}$ & $-0.294(-1.71)$ & $0.29(1.71)$ & $-0.84(-3.15)^{* * *}$ \\
\hline Married (=1) & $0.146(1.06)$ & $-0.14(-1.06)$ & $0.141(0.72)$ \\
\hline Constant & $1.116(3.09)^{* * *}$ & $-1.11(-3.09)^{* * *}$ & $0.49(1.09)$ \\
\hline $\begin{array}{l}\text { Number of } \\
\text { observations }\end{array}$ & 5036 & 5036 & 5036 \\
\hline \multicolumn{4}{|c|}{$\begin{array}{l}\text { Durbin-Wu-Hausman } \\
0.006^{*}\end{array}$} \\
\hline \multicolumn{4}{|c|}{$\begin{array}{l}\text { Sargan } \quad \text { statistic } \\
0.45036(p=0.5732)\end{array}$} \\
\hline Basmann & statistic & of & instruments) \\
\hline
\end{tabular}




\begin{tabular}{|l|l|l|l|}
\hline Variables & $\begin{array}{l}\text { Public provider } \\
\text { (Coefficient } \\
\text { estimates })\end{array}$ & $\begin{array}{l}\text { Private provider } \\
\text { (Coefficient } \\
\text { estimates })\end{array}$ & $\begin{array}{l}\text { Semi-private } \\
\text { provider } \\
\text { (Coefficient } \\
\text { estimates })\end{array}$ \\
\hline $0.45024(\mathrm{p}=0.5733)$ & chi2(42) \\
\hline $\mathrm{F}(2,5036)$ & \\
\hline $\begin{array}{l}\text { LR } \\
1535.2\end{array}$ & \\
\hline Log $* * *$ \\
3602.8167
\end{tabular}

Source: Researcher's own construction

Table A1 in the appendix presents the marginal effects for the provider choice model. Considering the public treatment alternative, the results show that a 1 FRW increase in price of health care is associated with a 0.49 decrease in the probability of choosing private provider. The results further show that a 1 FRW increase in fees would increase the probability of choosing the public service providers by 0.09 . If this seems surprising, it shows that user fees is not a constraint for using health services from public institutions because they charge less as compared to the private ones.

Further, living in urban areas as compared to rural increases the probability of choice of a private provider by 0.16 . This is as expected because urban people earn higher incomes than their rural counterparts and can afford private health services.

\section{REFERENCES}

1. Acton J. P. (1975). Nonmonetary Factors in the Demand for medical services: Some empirical Evidence. The Journal of Political economy, Vol. 83, No. 3, 595-614.

2. Ajakaiye O. and G. Mwabu (2007). The Demand for reproductive health services: An Application of Control function Approach. AERC, Nairobi.

3. Akin J. S., D. K. Guikey and M. McIntosh (1998). Price Elasticities of demand for Curative care with Control for sample Selectivity on endogenous illness: An analysis for Sri Lanka. Health economics, Vol. 7(6: 509-531).

4. Awoyemi T. T., O. A. Obayelu and H. I. Opaluwa (2011). Effect of Distance on Utilization of Health Care Services in Rural Kogi State, Nigeria. J Hum Ecol, 35(1): 1-9. 
5. Bolduc D. C. Muller and G. Lacroix (1996). The Choice of Medical Providers in Rural

6. Benin: A Comparison of Discrete Choice Models. Journal of Health Economics, 15:477-498.

7. Brown C. J., J. A. Pagán and E. Rodríguez-Oreggia (2002). Inequality in Health Care Utilization in Mexico, Working Paper.

8. Feng J., Q. Bei and Y. Yangyang (2008). Wealth, Education and Demand for Medical Care. Evidence from Rural China. World Scientific, 215-30.

9. Gertler P. and L. Sanderson (1987). Are User Fees Regressive? The welfare Implications of Health Care Financing Proposals in Peru. Journal of econometrics, 36: 67-88.

10. Gertler P. and J. Van det Gaag (1990). Willingness to pay for medical care: evidence from two developing countries, Johns Hopkins University Press, Baltimore, MD.

11. Greene W.L. (2007). Econometric Analysis. New York. Macmillan Publishing Company.

12. Hahn B. (1994). Health Care Utilization: The Effect of Extending Insurance to Adults on Medicaid or Uninsured. MEDICAL CARE, Volume 32, Number 3, pp 227-239.

13. Hausman J.A. and McFadden D. (1984). Specification Tests for Multinomial Logit Model. Econometroca, 52, pp 1219-1240.

14. Heller P. (1982). A model of the demand for medical and health services in Peninsular Malaysia. Social Science and Medicine, 16(3), 267-284.

15. Hotchkiss D. P., L. Hutchinson, A. Malaj and A. Berruti (2004). Out-of-Pocket Payments and Utilization of Health Care Services in Albania: Evidence from Three Districts, Partners for Health Reform plus.

16. Hunt-McCool J., B. F. Kiker and Y. C. Ng, (1994). Estimates of the Demand for Medical Care Under Different Functional Forms. Journal of Applied Econometrics, Vol. 9, No. 2.

17. Hutchinson P. (1999). Health Care in Uganda Selected Issues. World Bank. No. 404.

18. Jayaraman A. S. Chadndrasekhar and T. Gebreselassie (2008). Factors affecting maternal healthcare seeking in Rwanda. USAID. Working Paper.

19. Odwee J. J.A., O. N. Okurutu and A. Adebua (2006). The determinants of health care demand in Uganda: The case study of Lira District. Northern Uganda, AERC Research, Paper 155.

20. Jowett M., A. Deolalikar and P. Martinsson (2004). Health insurance and treatment seeking behaviour: evidence from a lowincome country. Health Economics, 13: 845-857.

21. Kaija D. O. and P. O. Okwi (2011). Quality and Demand for Health Care in Rural Uganda: Evidence from 2002/03 Household Survey, Economic Research Consortium, Nairobi.

22. Kabubo-Mariara J. D. Mwabu and G.K. Nd'enge (2009). The Consequences of Fertility for Child Health in Kenya: Endogeneity, Heterogeneity and the Control Function Approach. AERC, Nairobi. 
23. Kioko M. U. (2009). The Economic Burden of Malaria in Kenya: A Household Level Investigation. PhD Thesis, University of Nairobi.

24. Lacriox G. and E. Alihonou (1982). An Empirical Model of Primary Health care Demand in Benin. Working Paper, Laval university.

25. Lawson D. (2004). A Microeconomic Analysis of Health, Health Care and Chronic Poverty. Unpublished, The university of Nottingham.

26. Lépine A. and A. Nestour (2008). Health Care Utilization in Rural Senegal: the Factors before the Extension of Health Insurance to farmers. International labor office, Research Paper, no. 2.

27. Li M. (1996). The demand for Medical Care: Evidence from Urban Areas in Bolovia. Living Standards Measurement Study Paper No. 12,. World Bank, Washington D.C.

28. Lindelow M. (2002). Health Care Demand in Rural Mozambique: Evidence from 1996/97, Household Survey. International Food Policy Research Institute (IFPRI), FCND, Discussion Paper, No. 126.

29. Luce R. D. (1959). Individual Choice Behavior: A theoretical analysis, New York, NY: John Willey and Sons, Inc.

30. McFadden D. (1981). Econometric Models of Probabilistic Choice in: Manski, C. and McFadden, D. (Eds). Structural Analysis of Discrete Data with Econometric Applications: Cambridge, MA, MIT Press.

31. Mocan N. H., E. Tekin and S. Z. Jeffrey (2004). The Demand for Medical Care in Urban China. World Development, Vol. 32, No. 2, pp. 289-304, 2004.

32. Muriithi M. K. (2009). The demand for Health Care in Nairobi Slum: The Role of Quality and Information. $\mathrm{PhD}$ Thesis, University of Nairobi.

33. Muriithi M. K., (2013). The Determinants of Health Seeking behavior in a Nairobi Slum-Kenya. European Scientific Journal, edition vol.9, No.8 ISSN: $1857-7881$.

34. Mwabu G. (1986). Health care Decisions at the Household Level: Results of a Rural Health

35. Survey in Kenya. Social Science and Medicine. Vol. 22, No. 3. pp. 315-319.

36. Mwabu G. (1989a). Referral System and Health Care Seeking Behavior of Patients: An Economic Analysis. World Development.Vol.17, No.1. pp.85-92.

37. Mwabu G., M. Ainsworth and A. Nyamete (1993). Quality of Medical Care and Choice of Medical Treatment in Kenya. An Empirical Analysis. Journal of Human Resources 28(4): 283- 291.

38. Mwabu G. J., B.Wang'ombe and B. Nganda (2003). The Demand for Medical Care in Kenya. African Development Bank, Oxford, OX4 2DQ, UK and 350 Main Street, Malden, MA 02148, USA.

39. National Institute of Statistics of Rwanda (NISR), (2006). Integrated Household Living Conditions Survey in Rwanda (2005-2006), Kigali: NISR.

40. Odwee, J. A.O, F. N. Okurut and A. Adebua (2006). The determinants of health care demand in 
41. Uganda: The case study of Lira District, Northern Uganda. AERC, Nairobi.

42. Rosenzweig M. R., T. P. Schultz (1982). The Behavior of Mothers as Inputs to Child Health: The Determinants of Birth Weight, Gestation, and the Rate of Fetal Growth. 53-92, in: Fuchs, Victor R., ed., Economic Aspects of Health, Chicago: The University of Chicago Press.

43. Sahn D. E., S. D. Younger and G. Genicot (2003). The Demand for Health Care Services in Rural Tanzania. Oxford Bulletin of Economics and Statistics, 65, (2): 241-259.

44. Shimeles A. (2010). Community Based Health Insurance Schemes in Africa: the Case of Rwanda. African Development Bank group, Working Paper, No. 120.

45. Ssewanyana S., O.J. Nabyonga, I. Kasirye and D. Lawson (2004). Demand for Health Care Services in Uganda, Implications for Poverty Reduction. Munich Personal RePEc archive, Unpublished.

46. Wong, E., B. Partin, D. Guilkey and J. Akin (1987). Accessibility Quality of Care and Prenatal Care use in the Philippines. Social Science and Medicines, 24 (11): 98.

47. Yoder, R. (1989). Are people willing and able to pay for health services? Social Science and Medicine, 29(1), 35-42. 


\section{APPENDIX TABLES}

Table A1: A Multinomial Logit Model of Provider Choice: Marginal Effects (zStatistics in Parentheses)

\begin{tabular}{|c|c|c|c|}
\hline Variables & Public provider & Private provider & $\begin{array}{l}\text { Semi private } \\
\text { provider }\end{array}$ \\
\hline Household income & $-0.0006(-0.79)$ & $0.0018(0.03)$ & $-0.002(-0.07)$ \\
\hline User fees & $0.0916(6.38) * * *$ & $-0.0489(-6.88) * * *$ & $-0.229(-2.04) * *$ \\
\hline $\begin{array}{l}\text { Quality of health care }(=1 \text { if } \\
\text { medical specialist in the visited } \\
\text { health facility exists })\end{array}$ & $0.116(3.25)^{* * *}$ & $0.07(2.48) * *$ & $0.024(0.61)$ \\
\hline Distance to the health facility & $-0.029(-0.79)$ & $-0.214(-2.94) * *$ & $-0.299(-3.53)$ \\
\hline Household size & $0.0024(0.44)$ & $-0.183(-1.74)^{*}$ & $0.260(1.69)^{*}$ \\
\hline Insurance (=1 if insured) & $0.0035(3.7) * * *$ & $0.021(1.78)^{*}$ & $0.0056(2.41)^{* *}$ \\
\hline Predicted values of insurance & $0.0043(4.1)^{* * *}$ & $0.0042(1.95)^{*}$ & $0.0083(2.6) * *$ \\
\hline Transportation cost & $-0.009(-3.03) * * *$ & $0.0123(4.19) * * *$ & $-0.005(-4.68) * * *$ \\
\hline No education $(=1)$ & $0.033(1.80)^{*}$ & $-0.0013(-0.11)$ & $0.82(0.23)$ \\
\hline Primary $(=1)$ & $0.065(2.5)^{* *}$ & $0.0004(1.91)^{*}$ & $0.045(0.78)$ \\
\hline Secondary $(=1)$ & $0.005(2.9) * * *$ & $0.0041(3.4)^{* * *}$ & $0.35(0.97)$ \\
\hline Tertiary $(=1)$ & $0.031(0.9)$ & $0.051(4.1)^{* * *}$ & $0.062(3.5)^{*}$ \\
\hline Age & $0.0016(2.05)^{* *}$ & $0.2057(2.46)^{* *}$ & $0.005(4.7) * * *$ \\
\hline Gender ( $=1$ if male) & $-0.034(1.30)$ & $0.036(-1.05)$ & $-0.024(-0.47)$ \\
\hline Location (=1 if urban) & $-0.06(-2.54)^{* *}$ & $0.159(3.32) * * *$ & $-0.07(-1.20)$ \\
\hline Kigali region $(=1)$ & $-0.011(-0.77)$ & $0.09(3.51)^{* * *}$ & $-0.135(-3.13) * * *$ \\
\hline Northern region $(=1)$ & $-0.0004(-0.05)$ & $0.042(2.41) * *$ & $-0.081(-2.67)^{* *}$ \\
\hline Marital status ( $=1$ if married) & $0.0191(0.81)$ & $-0.0476(-1.09)$ & $0.017(0.25)$ \\
\hline
\end{tabular}

Note: $* * *, * *$ and $*=$ significant at $1 \%, 5 \%$ and $10 \%$ level respectively

Source: Researcher's own construction 
Table A2: Determinants of the demand for Insurance, First Stage Regression (Provider Choice)

\begin{tabular}{|c|c|c|c|}
\hline Explanatory variables & Estimates & Standard errors & z-statistics \\
\hline Household income & 0.00023 & 0.00003 & $8.97 * * *$ \\
\hline User fees & -0.0173 & 0.0106 & -1.36 \\
\hline $\begin{array}{l}\text { Quality of health care ( }=1 \text { if medical specialist in the } \\
\text { visited facility exists) }\end{array}$ & 0.0152 & 0.0068 & $2.23 * *$ \\
\hline Distance to the health facility & -0.0605 & 0.0107 & $-5.61 * * *$ \\
\hline Household size & 0.0142 & 0.0012 & $11.39^{* * *}$ \\
\hline Age & 0.00063 & 0.00022 & $2.83^{* * *}$ \\
\hline Age squared & -0.0032 & 0.00075 & $-4.2 * * *$ \\
\hline Primary (=1) & 0.00035 & 0.000087 & $4.0^{* * *}$ \\
\hline Employment status (=1 if employed) & 0.006 & 0.0009 & $6.6^{* * *}$ \\
\hline Relationship to household head ( $=1$ if spouse) & 0.0002 & 0.00007 & $2.85^{* *}$ \\
\hline Secondary $(=1)$ & 0.0078 & 0.0054 & 1.4 \\
\hline Tertiary $(=1)$ & 0.00092 & 0.001 & 0.92 \\
\hline Male $(=1)$ & -0.00279 & 0.00589 & -0.47 \\
\hline $\operatorname{Urban}(=1)$ & -0.0982 & 0.0137 & $-7.16 * * *$ \\
\hline Kigali $(=1)$ & -0.0282 & 0.0114 & $-2.47 * *$ \\
\hline Southern $(=1)$ & -0.0590 & 0.0088 & $-6.7 * * *$ \\
\hline Western $(=1)$ & 0.0582 & 0.00872 & $6.67 * * *$ \\
\hline Northern $(=1)$ & 0.063 & 0.0083 & $7.59 * * *$ \\
\hline Transportation cost & 0.0045 & 0.00037 & 0.12 \\
\hline Marital status (=1 if married) & 0.0942 & 0.0075 & 12.44 \\
\hline Constant & -0.359 & 0.0146 & $-24.63 * * *$ \\
\hline \multicolumn{3}{|l|}{$\begin{array}{l}\text { Number } \\
5040\end{array}$} & observation $=$ \\
\hline $\begin{array}{l}\mathrm{F}( \\
68.23 * * *\end{array}$ & \multicolumn{2}{|c|}{$32145)$} & $=$ \\
\hline
\end{tabular}

Note: $* * *, * *$ and $*=$ significant at $1 \%, 5 \%$ and $10 \%$ level respectively Source: Researcher's own construction 
Table A3: Hausman Test of IIA assumption for the Choice of health provider $(\mathrm{N}=\mathbf{5 0 3 6})$

\begin{tabular}{|l|l|l|l|l|}
\hline Omitted & Chi2 & Df & P $>$ chi2 & Evidence \\
\hline Self-medication & $-232,000$ & 28 & 1 & for Ho \\
\hline Public & $-240,000$ & 25 & 1 & for Ho \\
\hline Private & -25.07 & 28 & 1 & for Ho \\
\hline Semi private & $-274,000$ & 32 & 1 & for Ho \\
& & & & \\
\hline
\end{tabular}

Ho: Odds (outcome $\mathrm{J}$ versus outcome K) are independent of other alternatives 